\title{
Calcium Increases in Pulmonary Alveolar Fluid in Lambs at Birth
}

\author{
DENNIS W. NIELSON AND MARGARET B. LEWIS
}

Department of Pediatrics, University of Utah, Salt Lake City, Utah 84132

\begin{abstract}
Calcium concentration in fetal lung fluid in lambs is relatively low, about $1.0 \mathrm{mEq} / \mathrm{liter}$, and its concentration in alveolar fluid in mature rabbits is about 3 $\mathrm{mEq} /$ liter. To see if the $\mathrm{Ca}^{++}$concentration changes at birth, we measured alveolar $\mathrm{Ca}^{++}$as soon as possible after delivery by cesarean section and the onset of ventilation in eight anesthetized lambs at 144 days gestation. Subpleural alveoli were punctured with $\mathrm{Ca}^{++}$selective microelectrodes as soon as $\mathbf{4} \mathrm{min}$ and as late as $\mathbf{2 2 0} \mathrm{min}$ after the onset of mechanical ventilation. The $\left[\mathrm{Ca}^{++}\right]$was $1.2 \pm 0.2 \mathrm{mEq} / \mathrm{liter}$ (mean $\pm \mathrm{SD}, n=8$ ) in fetal lung fluid collected before ventilation. After about 25 min of ventilation, alveolar $\mathrm{Ca}^{++}$ was not different from that in term lambs 24 to $72 \mathrm{~h}$ old $(3.3 \pm 0.6 \mathrm{mEq} / \mathrm{liter}, n=8)$. The $\left[\mathrm{Ca}^{++}\right]$increased with a $\mathrm{t}_{1 / 2}$ of about $10 \mathrm{~min}$. Thus, alveolar $\mathrm{Ca}^{++}$assumes a mature character very rapidly after the start of breathing in term lambs. (Pediatr Res 24: 322-325, 1988)
\end{abstract}

\section{Abbreviation}

PD, potential difference

Before birth the concentration of calcium in the fluid secreted by fetal lungs is relatively low, about $1 \mathrm{mEq} /$ liter $(1,2)$. Recently we found that the concentration of ionized calcium in the alveolar fluid of mature rabbits was $3.2 \pm 0.4 \mathrm{mEq} /$ liter, measured by an alveolar micropuncture technique (3). Thus, if postnatal lambs achieve a similar $\mathrm{Ca}^{++}$concentration, there is a 3fold increase in alveolar $\mathrm{Ca}^{++}$between fetal and air-breathing life.

Similar to calcium, the concentration of chloride in fetal lung fluid is much different than it is in alveolar lining fluid in mature lungs. It is about $150 \mathrm{mEq} /$ liter in the fetal fluid $(1,2)$ and about $100 \mathrm{mEq} /$ liter in the mature lung fluid (3). In another study using micropuncture techniques (4), we found that the chloride concentration in the alveolar fluid decreased rapidly after the onset of air breathing in newborn lambs. This decrease fit well with a first order kinetic equation and had a $t_{1 / 2}$, the time to complete one half of the total change, of about $11 \mathrm{~min}$. Given this information, we wondered how rapidly alveolar $\mathrm{Ca}^{++}$increases in the minutes and hours after birth. To measure the change in alveolar $\mathrm{Ca}^{++}$, we applied the same alveolar micropuncture method used to describe the change in alveolar chloride at birth (4).

\section{METHODS}

Eight time-dated, pregnant ewes of Western mixed breed were anesthetized at 144 days gestation with ketamine $(30 \mathrm{mg} / \mathrm{kg})$

Received December 8, 1987; accepted May 9, 1988.

Correspondence Dennis W. Nielson, M.D., Ph.D., Department of Pediatrics, University of Utah, 50 North Medical Drive, Salt Lake City, UT 84132.

Supported in part by the National Heart, Lung and Blood Institute Grant HL28165 and by the Cystic Fibrosis Foundation Grant R0077. given intramuscularly, followed by additional doses intravenously to maintain anesthesia. After a midline incision and hysterotomy, the uterus was externalized and covered with blankets and a heating pad to minimize heat losses. The head and neck of the fetus were delivered and a tight fitting, latex glove was placed over the fetal head to prevent spontaneous respiration. After local anesthesia (1\% lidocaine subcutaneously) and a midline incision of the neck, the trachea was located and clamped.

A sample of fetal lung fluid was removed by inserting a 16gauge needle between two of the tracheal rings and then passing a catheter through the needle and into the airway. A total of 5$6 \mathrm{ml}$ of fetal lung fluid were removed and set aside for analysis. A snugly fitting endotracheal tube was placed and tied securely in the tracheal lumen, and then this tube was clamped so that no lung fluid escaped.

After placing the endotracheal tube in three lambs, the lung fluid drained until flow stopped. Sequential aliquots of the draining fluid were analyzed for concentrations of $\mathrm{Ca}^{++}, \mathrm{Na}^{+}$, and $\mathrm{K}^{+}$ with ion selective electrodes.

Catheters were placed in the right carotid artery and the internal jugular vein. Arterial pressures and heart rate were measured continuously, and intermittent blood samples from the catheter provided information about the steady state gas exchange of the lamb. While still connected to the placenta, the lamb was moved to a warming table inside a Faraday cage. It was dried and wrapped in blankets to minimize evaporative heat losses. A rectal temperature probe was inserted to monitor body temperature continuously. After injecting $1 \%$ lidocaine, an incision was made at the level of the third intercostal space and the right upper lobe exposed. D-Tubocurarine $(1 \mathrm{mg})$ was injected intravenously to prevent spontaneous respiratory efforts. At this point mechanical ventilation of the lung started (Harvard, model 681 , tidal volume $=10 \mathrm{ml} / \mathrm{kg}$ ) and the simultaneously the umbilical cord was clamped. Supplemental oxygen was added to the inspired gas to maintain arterial partial pressure of oxygen above 100 torr, and the ventilator rate was adjusted to achieve a $\mathrm{PaCO}_{2}$ of 35 to 40 torr. Additional anesthesia was given to the lamb every $60 \mathrm{~min}$ (ketamine $10 \mathrm{mg} / \mathrm{kg}$ intramuscularly).

Alveolar micropuncture began as soon as possible after the onset of ventilation of the lung. A small plastic restrainer, described previously (4), was attached to the lung by suction and an adhesive (Super Glue, Loctite Corp., Cleveland, $\mathrm{OH}$ ). An electrolyte solution warmed to $39 \pm 1^{\circ} \mathrm{C}$ bathed the lung surface. This solution contained $136 \mathrm{mEq} /$ liter $\mathrm{Na}^{+}, 4.0 \mathrm{mEq} / 1 \mathrm{~K}^{+}, 3.0$ $\mathrm{mEq} /$ liter $\mathrm{Ca}^{++}, 110 \mathrm{mEq} /$ liter $\mathrm{Cl}^{-}$, and $25 \mathrm{mEq} /$ liter lactate with a $\mathrm{pH}=7.0$. The $\left[\mathrm{Ca}^{++}\right]$of 3.0 was chosen so that there would be little or no concentration gradient between the fluid on the lung surface and the interstitium. A cotton wick in the restrainer that was saturated with the electrolyte solution made electrical contact with the visceral pleural surface. A calomel cell touching the wetted cotton wick served as the reference side of the measuring circuit. A calcium-selective microelectrode or a 3 $\mathrm{M} \mathrm{KCl}$ electrode was attached to a micromanipulator and connected to an electrometer (World Precision Instruments, New Haven, CT, model FD 223). 
The measurements of ionic concentration and alveolopleural PD proceeded as before $(3,4)$ with a microelectrode selective for $\mathrm{Ca}^{++}$or with a nonselective $\mathrm{KCl}$ electrode. Before each alveolar measurement, a baseline potential was recorded by immersing the microelectrode tip in the calibrating fluid on the lung surface. The respiratory movements were stopped at end-inspiration. With continuous observation through a stereomicroscope (M5Apo, Wild, Heerbrugg), the microelectrode tip penetrated the pleura and entered the alveolar space. After recording a stable potential for $20 \mathrm{~s}$, the electrode was withdrawn, ventilation of the lung resumed, and the baseline potential remeasured. Electrode position was controlled with a micromanipulator (Leitz, Germany). No alveolus was punctured more than once.

Serum samples taken before the onset of ventilation and at the end of each experiment were analyzed for $\left[\mathrm{Ca}^{++}\right],\left[\mathrm{Na}^{+}\right]$, and $\left[\mathrm{K}^{+}\right]$with ion-selective electrodes. At the end of each experiment the lambs were killed by anesthetic overdose followed by a lethal injection of $\mathrm{KCl}$ solution. The ewes were killed similarly immediately after cord clamping.

Eight lambs were studied 24 to $72 \mathrm{~h}$ after spontaneous birth. They were anesthetized with intramuscular ketamine $(30 \mathrm{mg} /$ $\mathrm{kg}$ ), supplemented at 50-min intervals, and alveolar micropuncture performed as outlined above. Alveolar $\left[\mathrm{Ca}^{++}\right]$and the alveolopleural PD were measured.

The ion-selective microelectrodes were constructed as previously described $(3,4)$. Each electrode was calibrated at $39^{\circ} \mathrm{C}$ with electrolyte solutions of the appropriate ion at four concentrations with a range encompassing that expected for the alveolar measurements. A least squares calculation yielded a slope, intercept, and correlation coefficient for each electrode. After taking the mean alveolopleural PD into account, alveolar concentration was calculated from the ion-selective electrode data with the equation of the calibration line.

The PD between the pleural surface and the alveolar lining was measured with a $\mathrm{KCl}$ electrode $\left(1\right.$ to $2 \times 10^{-6} \mathrm{~m}$ beveled tip). The reference electrode for all measurements was a calomel cell in contact with the visceral pleura through a small cotton wick saturated with Ringer's solution. The electrical circuit was the same as in our previous report (3). The electrometer had an input impedance of $10^{15} \mathrm{ohms}$. All experiments took place in a Faraday cage.

\section{RESULTS}

Vital signs of the lambs remained stable throughout the experiments. Body temperature was 38 to $39^{\circ} \mathrm{C}$ when the lambs were placed on the warming table and maintained in that range throughout each experiment. Mean blood pressure was 60 to 80 $\mathrm{mm} \mathrm{Hg}$, except during alveolar micropuncture procedures, after which it returned to baseline within $60 \mathrm{~s}$ of resuming ventilation. Peak inspiratory pressure was $29 \pm 8 \mathrm{~cm} \mathrm{H}_{2} \mathrm{O}$ at the start of mechanical ventilation, and it decreased to $20 \pm 9 \mathrm{~cm} \mathrm{H}_{2} \mathrm{O}$ within $30 \mathrm{~min}$. The lung appeared healthy and well perfused throughout each experiment.

Alveoli could not be punctured until they could be seen clearly, which usually occurred about 5 min after starting mechanical ventilation. The criteria for an acceptable alveolar measurement were as before $(3,4)$ : the electrode potential must arrive at and maintain a steady state, there must be no bleeding, and the baseline electrode potential must not change more than $1 \mathrm{mV}$ during the measurement. Approximately two-thirds of micropuncture attempts met these criteria, and the resulting measurements produced data with shape and time course (Fig. 1) similar to in vitro measurements. Measurements were made successfully from 4 to $220 \mathrm{~min}$ after the start of mechanical ventilation. Occasionally, two measurements were made in rapid succession, so that the lungs were not ventilated for a maximum of $30 \mathrm{~s}$ with each, but then 10 to 20 min were allowed for recovery.

It was impossible to obtain a time zero measurement of alveolar calcium by micropuncture, but the calcium concentration in the lung fluid removed from the airway before onset of

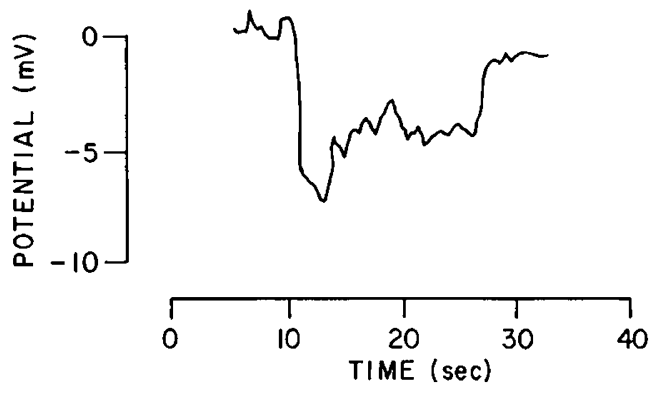

Fig. 1. Typical time course for the $\mathrm{Ca}^{++}$microelectrodes during alveolar micropuncture. The baseline potential, taken as zero, from time $=0$ to $10 \mathrm{~s}$ was generated by the electrode in the electrolyte solution on the pleural surface. That solution had a $\left[\mathrm{Ca}^{++}\right]$of $3.0 \mathrm{mEq} /$ liter. At $10 \mathrm{~s}$ an alveolus is punctured. The electrode was withdrawn at time $=27 \mathrm{~s}$, and the electrode potential then returned to baseline.

ventilation was equal to the alveolar concentration. Sequential samples of lung fluid did not change in composition. Using duplicate measurements in three lambs, the initial aliquots had concentrations of $\mathrm{Ca}^{++}, \mathrm{Na}^{+}$, and $\mathrm{K}^{+}$of $1.2 \pm 0.2,142 \pm 2$, and $6.4 \pm 1.7 \mathrm{mEq} /$ liter (mean $\pm \mathrm{SD}, n=6$ ). The final aliquots, which were obtained after 30 to $35 \mathrm{ml}$ of fetal lung fluid had drained, had concentrations of $1.4 \pm 0.3,146 \pm 5$, and $5.9 \pm 1.3$ $\mathrm{mEq} /$ liter. These three lambs weighed $3.4,4.7$, and $5.1 \mathrm{~kg}$, so that the anatomic dead space in each would be about 5 to $10 \mathrm{ml}$ (1.5 to $2.1 \mathrm{ml}$ dead space $/ \mathrm{kg}$ body weight). Inasmuch as the volume of lung fluid removed was three to seven times more than dead space volume, the final samples were alveolar liquid.

Alveolar calcium increased very rapidly after the onset of air breathing (Fig. 2) from an initial value of $1.2 \pm 0.2$ (mean $\pm \mathrm{SD}$, $n=8$ ) to $3.1 \pm 0.2 \mathrm{mEq} /$ liter (time $=40$ to $220 \mathrm{~min}, n=24$ ). The increase in alveolar calcium was seen in all experiments. Unfortunately, not enough early points were obtained to perform a formal kinetic analysis of this process, but from the data (Fig. 2 ) it appears that the $t_{1 / 2}$, the time for one-half of the concentration change to occur, was roughly $10 \mathrm{~min}$.

Serum composition did not change during the experiments in the newborn lambs. Before the onset of ventilation and at the end of the experiments, serum $\left[\mathrm{Na}^{+}\right]$was $143 \pm 5$ and $142 \pm 6$ $\mathrm{mEq} / \mathrm{liter},\left[\mathrm{K}^{+}\right]$was $4.2 \pm 0.7$ and $3.9 \pm 0.7 \mathrm{mEq} / \mathrm{liter}$, and $\left[\mathrm{Ca}^{++}\right]$was $3.3 \pm 0.3$ and $3.0 \pm 0.4 \mathrm{mEq} /$ liter (mean $\pm \mathrm{SD}, n=$ 8). Consequently, there was no significant concentration gradient for these ions between the fluid that bathed the lung surface, blood, and interstitium.

The alveolar concentration of $\mathrm{Ca}^{++}$in the 1- to 3-day-old lambs was $3.3 \pm 0.6($ mean $\pm \mathrm{SD}, n=8)$. This is equal to that in the newborn lambs at $>40$ min and in mature rabbits (3). Also, the concentration of $\mathrm{Ca}^{++}$in the tracheal fluid $(1.2 \pm 0.2$, mean $\pm \mathrm{SD}, n=8)$ is similar to that reported elsewhere $(1,2)$. Serum composition was similar to that in the lambs delivered by cesarean section and did not change during these experiments.

The alveolopleural PD in the first few hours after birth, -1.5 $\pm 0.6 \mathrm{mV}$ (mean $\pm \mathrm{SD}, n=43)$, was significantly different $(p<$ 0.001 ) from that measured in the 1 - to 3 -day-old lambs, $-2.9 \pm$ $0.5 \mathrm{mV}(n=32)$. The PD did not change measurably during any experiments, and the PD was negative with respect to the visceral pleura. Because the impedance of the $\mathrm{KCl}$ electrodes was lower than that of the ion-selective electrodes, their response was faster and they had no measurable baseline drift (Fig. 3).

\section{DISCUSSION}

Alveolar $\left[\mathrm{Ca}^{++}\right]$increased rapidly after the onset of air breathing (Fig. 2) with a time course similar to the change in alveolar chloride we observed previously in similar experiments (4). In that previous work, alveolar chloride decreased after the onset of ventilation of the lungs from about 150 to $100 \mathrm{mEq} / \mathrm{liter}$ with a $t_{1 / 2}$ of $11 \mathrm{~min}(4)$, not very different from that estimated graphi- 


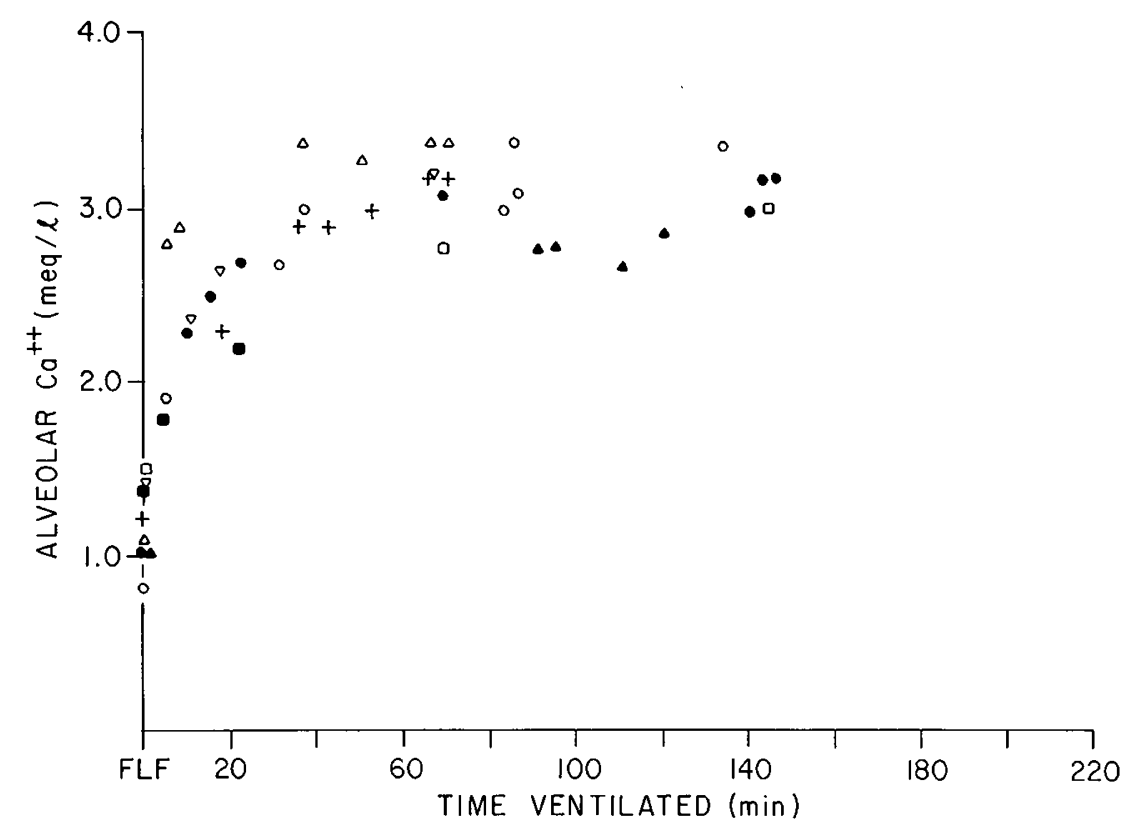

Fig. 2. Increase in alveolar $\mathrm{Ca}^{++}$in eight lambs during mechanical ventilation. The time zero value is the concentration of $\mathrm{Ca}^{++}$in the fetal lung fluid sample taken from each of these lambs before starting ventilation. The remaining points were obtained by alveolar micropuncture with $\mathrm{Ca}^{++}$sensitive microelectrodes after starting mechanical ventilation of the lungs. The different symbols correspond to the eight lambs studied.

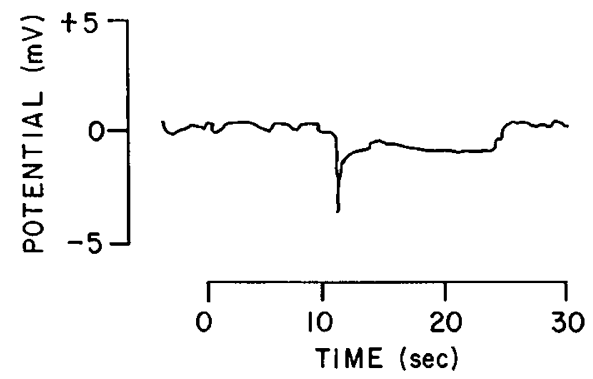

Fig. 3. Typical time course for the $3 \mathrm{M} \mathrm{KCl}$ microelectrode. The baseline potential, taken as zero, was generated with the electrode in the electrolyte solution on the pleural surface. At time $=11 \mathrm{~s}$ the electrode punctured an alveolus. At time $=24 \mathrm{~s}$ it was withdrawn from the alveolus, and the potential returned to baseline.

cally from the data in this study. The rapidity of the change and the difficulty of the experimental technique made it impossible to obtain many early measurements, but alveolar $\left[\mathrm{Ca}^{++}\right]$in 1 - to 3-day-old lambs, $3.3 \pm 0.6 \mathrm{mEq} /$ liter, was the same as the steady state concentration measured in the cesarean section lambs, 3.2 $\pm 0.2 \mathrm{mEq} /$ liter (Fig. 2). Clearly the change in concentration occurred in minutes rather than hours or days.

Although we were unable to obtain any micropuncture measurements of alveolar $\mathrm{Ca}^{++}$in the fluid-filled lung, there was no difference between the composition of the fluid exiting the trachea and the fluid in the fetal alveoli. Inasmuch as the dead space, the volume of the airways, is small, the fluid samples after removing 5 to $10 \mathrm{ml}$ were alveolar. We found no difference in composition in any of the sequential samples in these lambs and in additional experiments not reported here. Previous measurements of sequential samples of fetal lung fluid by Adamson et al. (1) yielded identical results.

As in our previous work (4), the potential measured between the pleural surface and the alveolar interior in the first $220 \mathrm{~min}$ of air breathing was less negative than the alveolopleural PD in the 1- to 3-day-old lambs. The significance of this finding is difficult to assess because the source of this potential in the complex structure of the terminal respiratory unit is not known. Also, this potential is very small, and the difference between it and the PD we measured in more mature animals is even smaller. The difference might be due to an increase in transepithelial conductance caused by a transient increase in mean pore size that occurs with the onset of air breathing $(4,5)$.

Measurement of ionic concentrations in the alveolar subphase in vivo is a relatively new and uncommon approach to the study of alveolar fluid, so that no great body of experience exists. However, the results of this approach have been very reproducible in the few studies completed to date $(3,4,7)$. Further, it is unlikely that other ions or charged species in alveolar fluid interfered with the alveolar measurements in view of the excellent selectivity of the ion exchange resin (6). It is $6 \times 10^{4}$ more selective for $\mathrm{Ca}^{++}$than for $\mathrm{Mg}^{++}$, and it is $5 \times 10^{7}$ more selective for $\mathrm{Ca}^{++}$than for $\mathrm{Na}^{+}$or $\mathrm{K}^{+}$. Also, contamination of the alveolar fluid by the electrolyte solution on the lung surface has not been a significant problem $(3,7)$, and making small but measurable changes in the electrolyte solution of the lung surface does not affect the alveolar concentration of $\mathrm{Ca}^{++}, \mathrm{Na}^{+}, \mathrm{K}^{+}$, or $\mathrm{Cl}^{-}(3)$.

Measuring alveolar concentrations in intact, anesthetized lambs has advantages. The lungs are in as near normal a state as has been studied to date, and the transition from fetal to airbreathing life can be studied in a way not accessible by other techniques. However, this approach does not define bulk fluid movement or allow measurement of ion fluxes across the alveolar epithelium.

Based on all of the above, it appears that the concentration of $\mathrm{Ca}^{++}$in the alveolar subphase rapidly increases after the start of air breathing, achieving a "mature" composition within minutes. The $\mathrm{Ca}^{++}$concentration achieved is sufficient to ensure optimal function of lung surfactant $(8-10)$, but the mechanism of that change is not known. The results of this study do not distinguish between clearance of water and secretion of $\mathrm{Ca}^{++}$into the alveolar lumen as the source of increased $\mathrm{Ca}^{++}$concentration. However, because the $\mathrm{Cl}^{-}$concentration decreases at the same rate that $\mathrm{Ca}^{++}$increases (4), both changes cannot be due only to clearance of water from the alveoli. If the movement of ions across the alveolar epithelium during the transition to air breathing life is active or passive seems approachable with additional experiments of the type reported in this work.

\section{REFERENCES}

1. Adamson TM, Boyd RDH, Platt HS, Strang LB 1969 Composition of alveolar liquid in the foetal lamb. J Physiol (Lond) 204:159-168

2. Mescher EJ, Platzker ACG, Ballard PL, Kitterman JA, Clements JA, Tooley WH 1975 Ontogeny of tracheal fluid, pulmonary surfactant, and plasma 
corticoids in the fetal lamb. J Appl Physiol 39:1017-1021

3. Nielson DW 1986 Electrolyte composition of pulmonary alveolar subphase in anesthetized rabbits. J Appl Physiol 60:972-979

4. Nielson DW 1988 Changes in the pulmonary alveolar subphase at birth in term and premature lambs. Pediatr Res 23:418-422.

5. Egan EA, Olver RE, Strang LB 1975 Changes in the nonelectrolyte permeability of alveoli and the absorption of lung liquid from the lungs of the lambs at the start of breathing. J Physiol (Lond) 244:161-179

6. Brown HM, Pemberton JP, Owen JD 1976 A calcium-sensitive microelectrode suitable for intracellular measurement of calcium (II) activity. Anal Chim
Acta 85:261-276

7. Nielson DW, Goerke J, Clements JA 1981 Alveolar subphase $\mathrm{pH}$ in the lungs of anesthetized rabbits. Proc Natl Acad Sci USA 78:7119-7123

8. Benson BJ, Williams MC, Sueishi K, Goerke J, Sargeant T 1984 Role of calcium ions in the structure and function of pulmonary surfactant. Biochim Biophys Acta 793:18-27

9. Sanders RL, Hassett RJ, Vatter AE 1980 Isolation of lung lamellar bodies and their conversion to tubular myelin forms in vitro. Anat Rec 198:485-501

10. Gil J, Reiss OK 1973 Isolation and characterization of lamellar bodies and tubular myelin from rat lung homogenates. J Cell Biol 58:152-171 